\title{
EVALUATION OF GENETIC DIVERSITY AND RELATIONSHIPS IN MULBERRY VARIETIES USING RAPD AND ISSR MOLECULAR MARKERS
}

\section{CHIKKASWAMY B.K. ${ }^{*}$ AND PRASAD M.P. ${ }^{2}$}

${ }^{1}$ Department of Biotechnology, P.G. center R.K. Institute of Management and Computer Sciences, Bangalore-560 037, Karnataka, India. 2Sangenomics Research Labs, Bangalore-560071, Karnataka, India

*Corresponding Author: Email-drchikkaswamy@rediffmail.com

Received: September 06, 2012; Accepted: October 25, 2012

\begin{abstract}
Studies on genetic diversity and relationships between twenty different varieties of mulberry were assayed with selected RAPD and ISSR genetic markers. In the present investigation, the selected mulberry varieties were amplified with 16 RAPD and 8 ISSR primers. The results showed 70 reproducible bands out of which, 61 were polymorphic accounting $81.3 \%$ polymorphism with RAPD primers. In contrast, 43 polymorphic bands were generated by ISSR primers out of which 42 were polymorphic bands with $97.6 \%$ polymorphism. The primers used in the present study generated unique banding pattern in all the test varieties and most of the varieties exhibited unique molecular genotype. Population genetic structure analysis of these varieties also revealed high genetic differentiation coefficient (GST), heterozygosity among populations $(\mathrm{Ht})$ and low gene flow $(\mathrm{Nm})$. The dendrogram was generated using Ward's Euclidean distance and UPGMA methods. Based on the number of RAPD and ISSR bands, the mulberry varieties were grouped into 5 clusters. Among these, 5 th cluster was paired with other varieties. Based on the results obtained on cluster analyses, it is formulated that, 3 varieties of mulberry were considered as one group, whereas other 4 clusters may be included under separate group.
\end{abstract}

Keywords- Mulberry, RAPD, ISSR, Genotypes, Genetic Diversity.

Citation: Chikkaswamy B.K. and Prasad M.P. (2012) Evaluation of Genetic Diversity and Relationships in Mulberry Varieties Using RAPD and ISSR Molecular Markers. International Journal of Molecular Biology, ISSN: 0976-0482 \& E-ISSN: 0976-0490, Volume 3, Issue 3, pp.-62-70.

Copyright: Copyright@2012 Chikkaswamy B.K. and Prasad M.P. This is an open-access article distributed under the terms of the Creative Commons Attribution License, which permits unrestricted use, distribution and reproduction in any medium, provided the original author and source are credited.

\section{Introduction}

Mulberry belonging to the family Moraceae is the complete source of food materials for the silk worm, Bombyx mori widely practiced in sericulture. The fruits of some species of mulberry being edible are used as an ingredient in the preparation of mulberry wine, jam and juice. The foliage, being nutritious and palatable, is also used as cattle fodder. Mulberry is propagated asexually by grafting and some varieties are also propagated sexually. Although Mulberry is native to China, the white mulberry is cultivated throughout the world wherever silk worms are raised. Morus alba grows in warmer climatic zones of the world between $50^{\circ} \mathrm{N}$ latitude and $10^{\circ} \mathrm{S}$ latitude [1]. About 150 species of the genus Morus have been described and among these most of them have been considered as varieties of the same species. Presently it comprises about 68 identified species and are well distributed in Japan, China, India, Korea and Taiwan [2].

The major area of mulberry cultivation is the tropical zone covering Karnataka, Andhra Pradesh and Tamil Nadu states in India. In the sub tropical zone, West Bengal, Himachal Pradesh and the North-
Eastern states have major under mulberry cultivation. The species such as Morus alba, M. indica, M. serrata and M. laevigata are grown wild in the Himalayas. Mulberry bears both male and female and also bisexual flowers on the same plant (Monoecious) or on different plants (dioecious) with expression of sexual characters often depending on several physiological and biochemical factors [3]. Various varieties of mulberry have been developed through traditional breeding methods.

DNA finger printing techniques are efficient in identifying genetic differences at species level. The RAPD method is based on amplification of polymorphic DNA fragments by the polymerase chain reaction $(\mathrm{PCR})$ using single oligonucleotide primer with arbitrary sequence. This method described by [4] is similar to the arbitrarily primed PCR [5] and is a fast and simple approach. In addition, the reproducibility of RAPD banding patterns can be affected by different concentrations of reaction components and the cycle conditions [4]. RAPD technique has been shown to be useful in genetic $[6,7]$ and phylogenetic analyses [8-10], Inter Simple Sequence Repeats (ISSR) utilizes the primers based on microsatellites to amplify interSSR DNA sequences on SSR [11]. In this technique various micro 
satellites attached at the $3^{\prime}$ end are used to amplify genomic DNA. These markers are expressed dominant despite a few of them exhibit co-dominance. An unlimited number of primers can be synthesized for various combinations of di-, tri-, tetra- and pentanucleotides, etc. with an anchor made up of a few bases and can be exploited for a broad range of applications in plant species [12,13]. There are considerable differences of opinion in the classification of Morus based on morphological characteristics. Therefore, there is a great need to identify mulberry species at molecular level.

Thus, the present study was undertaken to investigate the interrelationships among twenty different mulberry varieties extensively distributed in Karnataka, India.

\section{Materials and Methods}

Leaf samples of twenty mulberry varieties/accessions were collected from the germplasms maintained by the Department of Sericulture, Bangalore University, University of Agricultural Sciences and Karnataka State Sericulture Research and Development Institute, Bangalore [Table-1]. The first 2-4 leaves from the tips were collected and used for DNA extraction.

Table 1- The list of 20 mulberry varieties/accessions used for the present study

\begin{tabular}{|c|c|c|c|c|c|c|}
\hline $\begin{array}{l}\text { S. } \\
\text { No. }\end{array}$ & $\begin{array}{l}\text { SMGS } \\
\text { Acc. No }\end{array}$ & Name & $\begin{array}{l}\text { Donor } \\
\text { Name }\end{array}$ & $\begin{array}{l}\text { Donor } \\
\text { Id. No. }\end{array}$ & $\begin{array}{l}\text { Countryl } \\
\text { State }\end{array}$ & Origin \\
\hline 1. & MI-0012 & $S-13$ & $\begin{array}{l}\text { RSRS, } \\
\text { Kodathi }\end{array}$ & -- & KAR & OPH selection \\
\hline 2. & MI-0045 & S-146 & $\begin{array}{l}\text { RSRS, } \\
\text { Kodathi }\end{array}$ & 208 & KAR & OPH selection \\
\hline 3. & MI-0160 & S-34 & $\begin{array}{l}\text { CSR\&TI, } \\
\text { Mysore }\end{array}$ & -- & KAR & Mutation \\
\hline 4. & MI-0308 & $V-1$ & $\begin{array}{l}\text { RSRS, } \\
\text { Kodathi }\end{array}$ & -- & KAR & $\mathrm{CPH}$ \\
\hline 5. & & M-5 & & & & \\
\hline 6. & MI-0052 & Mysore local & $\begin{array}{l}\text { CSR\&TI, } \\
\text { Mysore }\end{array}$ & 144 & KAR & Selection \\
\hline 7. & MI-0066 & R-175 & & & & \\
\hline 8. & MI-0021 & $\mathrm{DD}$ & $\begin{array}{l}\text { KSSRDI, } \\
\text { Bangalore }\end{array}$ & -- & UPR & Collection \\
\hline 9. & MI-0423 & Srinagar & $\begin{array}{l}\text { Expl. North- } \\
\text { West India }\end{array}$ & $\begin{array}{l}\text { AT96 } \\
\text { (1)29 }\end{array}$ & UPR & Collection \\
\hline 10. & MI-0025 & MR-2 & $\begin{array}{l}\text { RSRS, } \\
\text { Kodathi }\end{array}$ & 111 & TNU & $\begin{array}{l}\text { Clonal selec- } \\
\text { tion }\end{array}$ \\
\hline 11. & MI-0173 & S-1635 & $\begin{array}{c}\text { CSR\&TI, } \\
\text { Berhampore }\end{array}$ & -- & WBL & $\mathrm{OPH}$ selection \\
\hline 12. & & Karanahalli local & & & & \\
\hline 13. & MI-0013 & S-36 & $\begin{array}{l}\text { CSR\&TI, } \\
\text { Mysore }\end{array}$ & 157 & KAR & Mutation \\
\hline 14. & ME- 0050 & M. macroura & $\begin{array}{l}\text { CSR\&TI, } \\
\text { Mysore }\end{array}$ & 307 & JPN & Collection \\
\hline 15. & ME-0095 & M. rotundiloba & $\begin{array}{l}\text { CSR\&TI, } \\
\text { Mysore }\end{array}$ & 295 & BUR & Collection \\
\hline 16. & ME-0005 & Chinapeaking & $\begin{array}{l}\text { RSRS, } \\
\text { Kodathi }\end{array}$ & 147 & $\mathrm{PHI}$ & $\begin{array}{l}\text { Clonal selec- } \\
\text { tion }\end{array}$ \\
\hline 17. & ME-0107 & M. Ihou-seringe & $\begin{array}{c}\text { CSR\&TI, } \\
\text { Berhampore }\end{array}$ & -- & FRA & Collection \\
\hline 18. & ME-0065 & S-1 & $\begin{array}{l}\text { CSR\&TI, } \\
\text { Mysore }\end{array}$ & 139 & BUR & $\begin{array}{l}\text { Clonal selec- } \\
\text { tion }\end{array}$ \\
\hline 19. & MI-0024 & Assambola & $\begin{array}{l}\text { CSR\&TI, } \\
\text { Mysore }\end{array}$ & 105 & ASM & $\begin{array}{l}\text { Clonal selec- } \\
\text { tion }\end{array}$ \\
\hline 20. & MI-0047 & S-41 & $\begin{array}{l}\text { CSR\&TI, } \\
\text { Mysore }\end{array}$ & 158 & KAR & Mutation \\
\hline
\end{tabular}

Isolation and purification of total genomic DNA was carried out according to the protocol suggested by Porebski [14] with slight modifications. $2 \mathrm{~g}$ each of fresh leaf tissue was grinded with liquid nitrogen and was transferred to a tube containing $12 \mathrm{ml}$ of extraction buffer ( $3 \%$ CTAB, $100 \mathrm{mM}$ Tris, $20 \mathrm{mM}$ EDTA, $1.4 \mathrm{M} \mathrm{NaCl}, 2 \%$ PVP and $1 \% \beta$-mercaptoethanol) preheated to $65^{\circ} \mathrm{C}$ and kept at this temperature for 1 hour with continuous shaking. The centrifuge tube was spun at $7,000 \mathrm{rpm}$ for $15 \mathrm{~min}$ at $4^{\circ} \mathrm{C}$ in room temperature and supernatant collected was added with $6 \mathrm{ml}$ of chloroform and iso-amyl alcohol (24:1). The contents were mixed well by inverting the tube gently for 25-30 times and latter spun at 7,000 rpm for 15 $\min$ at $4^{\circ} \mathrm{C}$. The supernatant was transferred to a fresh tube and repeated the same steps thrice. Supernatant was kept overnight at $4^{\circ} \mathrm{C}$ to precipitate DNA by adding half a volume of $5 \mathrm{M} \mathrm{NaCl}$ and equal volume of iso-propanol by centrifuging at $12,000 \mathrm{rpm}$ for 20 min and the pellet obtained was washed with $70 \%$ ethanol. The dried DNA pellet was resuspended in $1 \mathrm{ml}$ TE buffer and added with $20 \mu \mathrm{l}$ RNase and incubated for $60 \mathrm{~min}$ at $37^{\circ} \mathrm{C}$. The DNA was further purified by treatment with an equal volume of phenol followed by an equal volume of phenol chloroform (1:1) and finally with an equal volume of chloroform. The DNA was precipitated by the addition of one volume of iso-propanol and spun at 12,000 rpm for 20 min at $4^{\circ} \mathrm{C}$. Finally, pellet was dissolved in $300 \mu \mathrm{TE}$. The DNA concentration was determined using UV-Visible spectrophotometer at $260 \mathrm{~nm}$ and $280 \mathrm{~nm}$ and the quality was verified by electrophoresis on a $0.8 \%$ agarose gel.

\section{RAPD}

The basic protocol suggested [15] were followed and the PCR cycles and buffer compositions were followed as per the standard methods [16]. Sixteen primers such as OPA-1, OPA-3, OPA-13, OPA-18, OPB-17, OPC-01, OPC-02, OPC-08, OPC-10, OPC-12, OPD-11, OPD-13, OPE-07, OPE-19, OPF-07 and OPF-17 were used in the present study. The amplification reactions were carried out in $25 \mu \mathrm{l}$ reaction mixture containing template DNA (30 ng), 10pmol of primer ( Operon technologies USA, Inc.), $1.5 \mathrm{mM}$ $\mathrm{MgCl}_{2}, 50 \mathrm{mM} \mathrm{KCl}, 10 \mathrm{mM}$ Tris-HCl,1U Taq DNA polymerase and $200 \mu \mathrm{M}$ of each dNTPs (Hi-media). The amplification was performed in the Corbett Research PCR machine (CG1-96) for 35 cycles after an initial denaturation at $94^{\circ} \mathrm{C}$ for $7 \mathrm{~min}$. In each cycle, denaturation for $1 \mathrm{~min}$ at $94^{\circ} \mathrm{C}$, annealing for $1 \mathrm{~min}$ at $35^{\circ} \mathrm{C}$ and extension for $2 \mathrm{~min}$ at $72^{\circ} \mathrm{C}$ was programmed with a final extension step at $72^{\circ} \mathrm{C}$ for $5 \mathrm{~min}$. Amplified DNA fragments were separated out on $1.4 \%$ agarose gel stained with ethidium bromide. Running buffer containing Tris-buffer, Boricacid and EDTA (pH 8.0) was used for electrophoresis and for preparation of gels. Wells were loaded with $25 \mu$ l reaction volume and $5 \mu$ l of loading buffer (Sucrose, Bromophenol blue and Xylenecyanol) together. Electrophoresis was conducted at 70 volts for 3 hours and the gel photographed under UV light using gel dock system (Herolab).

\section{ISSR}

PCR amplification of DNA was carried out [11]. ISSR analysis of genomic DNA of 20 varieties was carried out using 8 selected ISSR primers (UBC- 807, 809, 810, 811, 812, 820, 825 and 828) obtained from University of Columbia, Vancouver, Canada. The reaction was set up in a total volume of $20 \mu \mathrm{l}$ in a $0.2 \mathrm{ml} \mathrm{PCR}$ tube with 30ng Template DNA, 30 pmol Primer, $100 \mu \mathrm{M}$ dNTPs, 0.5U Taq DNA polymerase (Hi-Media), $10 \mathrm{mM}$ Tris $\mathrm{HCl}(\mathrm{pH} 8.4), 50 \mathrm{mM} \mathrm{KCl}$, $1.5 \mathrm{mM} \mathrm{MgCl}$. The amplification reaction was carried on Corbett 
Research PCR machine (CG1-96). The thermal profiles used were initial denaturation of $94^{\circ} \mathrm{C}$ for $5 \mathrm{~min}, 45$ cycles of denaturation at $94^{\circ} \mathrm{C}$ for $1 \mathrm{~min}$, annealing at $\mathrm{Tm}$ for $1 \mathrm{~min}$, extension at $72^{\circ} \mathrm{C}$ for 2 min and final extension at $72^{\circ} \mathrm{C}$ for $5 \mathrm{~min}$. The PCR amplified samples were assessed using 1.5\% Agarose gel.

Binary coding was used to score gel and each band of primer was scored for 20 varieties and 16 primers with 100 to 3000 base pairs marker level pair wise. Squared Euclidean distance and UPGMA were used to calculate the distances; varieties were clustered following Ward's method of Statistics version 5.0 a computer application and UPGMA method was used to generate dendrogram

\section{Genetic Relationship Among Genotypes}

The genetic relationships of different mulberry varieties and their grouping was assessed on the basis of the RAPD and ISSR markers using Nei's coefficients $(S=2 a b /(N a+N b))$ [17] and Dice's coefficients $(S=2 \mathrm{Nab} /(2 \mathrm{Nab}+\mathrm{Na}+\mathrm{Nb})$ [18] where $\mathrm{Nab}$ is the number of bands that are shared by genotypes $a$ and $b, \mathrm{Na}$ is the number of bands present in $a$ and $\mathrm{Nb}$ is the number of bands present in $b$; as well as Jaccard's coefficients $(S=\mathrm{NAB}(\mathrm{NAB}+\mathrm{Na}+$ $\mathrm{Nb}$ ) [19], where $\mathrm{Nab}$ is the number of bands that are shared by genotypes $a$ and $b, \mathrm{Na}$ is the number of bands present in $a$ and absent in $b$ and NB is the number of bands present in $b$ and absent in $a$.

Dissimilarity matrices were calculated from all of the above similarity matrices and dendrograms were generated using Wards Euclidean methods and UPGMA, [18] on PHYLIP 3.5c software program [20]. The robustness of the dendrogram was tested by estimating cophenetic correlation for each dendrogram and comparing it with the original ge-netic dissimilarity matrix, using Mantel's matrix correspon-dence test. Computing the cophenetic values and constructing the cophenetic matrices for each set of data, the differences between the dendrogram based on RAPD and ISSR and their pooled markers were assessed. These matrices generated from different methods were also tested for correlations using Mantel's test for matrix corre-spondence [21].

Further, relationships among the varieties were also investigated by analyzing the genotypes of each variety as a single population. The inter and intragenetic divergence was estimated using RAPD and ISSR markers. All the coefficients were also worked out for each variety and dendrogram were constructed to find out the genetic relationships among the varieties. The variability in the population was also calculated using Nie [22] coefficient of gene differentiation (Gst) in POPGENE, version 1.3 [23]. In POPGENE, the genetic divergence among different populations is calculated using a multiallelic analogue of Fst among a finite number of populations, which is otherwise called the coefficient of gene differentiations, [22]. This is stated in the following equation.

$$
\mathrm{G}_{\mathrm{ST}}=\mathrm{D}_{\mathrm{ST}} / \mathrm{H}_{\mathrm{t}}=\left(\mathrm{H}_{\mathrm{t}}-\mathrm{H}_{\mathrm{s}}\right) / \mathrm{H}_{\mathrm{t}}
$$

Where Dst is the average gene diversity between sub-populations, including the comparisons of subpopulations with themselves, with $D_{S T}=\left(H_{t}-H_{S}\right)$. $G_{S T}$ is an extension of Neis [24] genetic distance between a pair of populations to the case of hierarchical structure of populations $\mathrm{Nei} 25 \mathrm{Ht}$ is defined by the following equation:

$$
H_{t}=1-\Sigma P i^{2}
$$

Where $P i$ is the frequency of the allele at a locus in a population. $\mathrm{H}_{\mathrm{s}}$ was defined in terms of genetic diversities. However, in case of random mating subpopulations, genetic diversities are defined as expected heterozygosities under Hardy-Weinberg averaged among population $\left(\mathrm{H}_{\mathrm{s}}\right)$ and of the total population $\left(\mathrm{H}_{\mathrm{t}}\right)$. The main difference between $\mathrm{G}_{\mathrm{ST}}$ and $\mathrm{F}_{\mathrm{ST}}[25]$ is that in $\mathrm{G}_{\mathrm{ST}}$ the estimation of the heterozgosities relies on allele frequencies [26], whereas in $F_{S T}$, to estimate the $H_{s}$, the individual genotypes have to be known. The estimate of gene flow from Gst was calculated as follows.

$$
\mathrm{N}_{\mathrm{m}}=0.5\left(1-\mathrm{GST}_{\mathrm{ST}}\right) / \mathrm{G}_{\mathrm{ST}}
$$

\section{Results}

The results showed a good yield of 1000-3000 ng per $\mu \mathrm{l}$ for $2 \mathrm{~g}$ of leaf samples used. The DNA obtained in the present study was of high quality and responded well for amplification reactions. The readings of spectrophotometer -1.4-1.8 $(260 \mathrm{~nm} / 280 \mathrm{~nm})$ and gel electrophoresis confirmed the quality of DNA.

The amplification conditions were optimized to get high quality, intense, repeatable banding patterns, with varying concentrations of $\mathrm{Mg}^{2+}$ ions, primer and template DNA. An increase in the concentration of Mg2 primers has given clear, intense bands. But the increase in DNA concentration had no effect at least up to $50 \mathrm{ng} / 25 \mu \mathrm{l}$

In the study, a total of 120 arbitrary decamer, single stranded primers (OPA to OPF with 20 primers in each group) were utilized to screen the genomic DNA of mulberry genotypes. Among them, 28 primers on an average gave six bands. The following 16 primers were used in screening of varieties / accessions of mulberry (OPA01, OPA-03, OPA-13, OPA-18, OPB-17, OPC-01, OPC-02, OPC08, OPC-10, OPC-12, OPD-11, OPD-13, OPF-17, OPE-07, OPE19 and OPF -07), which generated 70 distinct markers. Both monomorphic and polymorphic bands were considered for the precise calculation of genetic diversity.

[Fig-1] and [Fig-2] show a representative DNA fingerprint generated by the RAPD and ISSR primers-809, UBC-811, UBC-830, UBC835 and UBC-86 and [Table-2], [Table-3], [Table-4] illustrate the list of random primers used in the present study. A dendrogram based on Ward's and UPGMA methods of analysis was presented in [Fig3], [Fig-4], [Fig-5], [Fig-6], [Fig-7], [Fig-8].

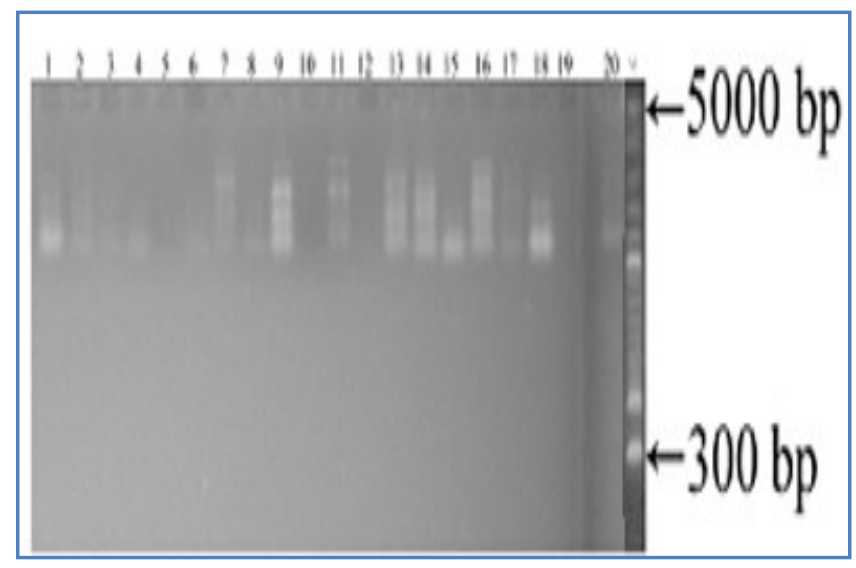

Fig. 1- Gel profile of 20 Varieties of mulberry amplified with RAPD primers OPD-11 


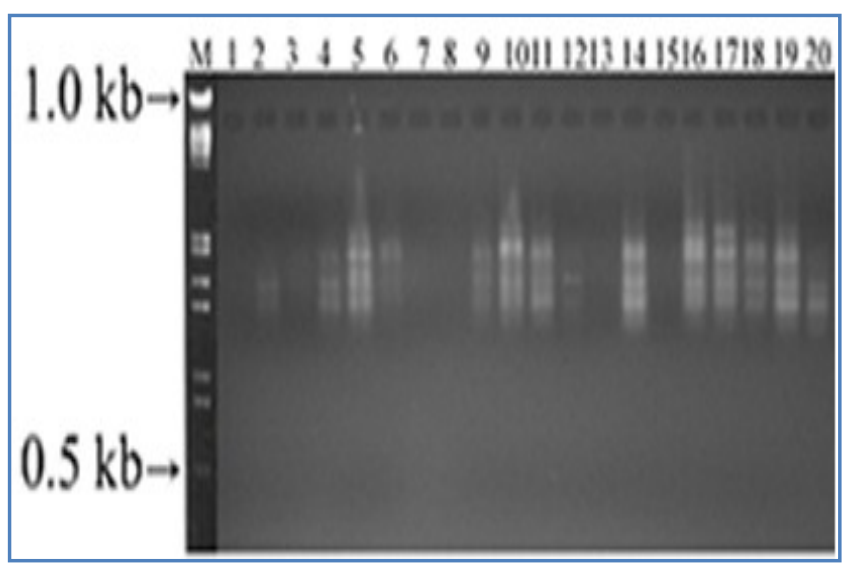

Fig. 2- Gel profile of 20 Varieties of Mulberry amplified with ISSE primer UBC-809

Table 2- List of the RAPD primers used

\begin{tabular}{|c|c|c|}
\hline S No & Primer & Sequence $\left(5^{\prime}-3^{\prime}\right)$ \\
\hline 1 & OPA-0 1 & CAGGCCCTTC \\
\hline 2 & OPA-03 & AGTCAGCCAC \\
\hline 3 & OPA-13 & CAGCACCCAC \\
\hline 4 & OPA-18 & AGGTGACCGT \\
\hline 5 & OPB-17 & AGGGAACGAG \\
\hline 6 & OPC-01 & TTCGAGCCAG \\
\hline 7 & OPC-02 & GTGAGGCGTC \\
\hline 8 & OPC-08 & TGGACCGGTG \\
\hline 9 & OPC-10 & TGTCTGGGTG \\
\hline 10 & OPC-12 & TGTCATCCCC \\
\hline 11 & OPD-11 & AGCGCCATTG \\
\hline 12 & OPD-13 & GGGGTGACGA \\
\hline 13 & OPE-07 & AGATGCAGCC \\
\hline 14 & OPE-19 & ACGGCGTATG \\
\hline 15 & OPF-07 & CCGATATCCC \\
\hline 16 & OPF-17 & AACCCGGGAA \\
\hline
\end{tabular}

Table 3- List of the ISSR primers used

\begin{tabular}{|c|c|c|}
\hline S No & Primer & Sequence $\left(5^{\prime}-3^{\prime}\right)$ \\
\hline 1 & UBC-807 & AGAGAGAGAGAGAGAGT \\
\hline 2 & UBC-809 & AGAGAGAGAGAGAGAGG \\
\hline 3 & UBC-810 & GAGAGAGAGAGAGAGAT \\
\hline 4 & UBC-811 & GAGAGAGAGAGAGAGAA \\
\hline 5 & UBC-812 & GAGAGAGAGAGAGAGAA \\
\hline 6 & UBC-814 & СТСТСТСТСТСТСТСТА \\
\hline 7 & UBC-825 & ACACACACACACACACT \\
\hline 8 & UBC-830 & TGTGTGTGTGTGTGTGG \\
\hline
\end{tabular}

Table 4- The genetic similarity coefficient estimated from the RAPD and ISSR and pooled markers in 20 genotypes of Mulberry

\begin{tabular}{lccc} 
& Maximum & Minimum & Mean \\
RAPD & 0.987 & 0.533 & 0.76 \\
Nei and Li & 0.46 & 0.373 & 0.416 \\
Dice & 0.842 & 0.333 & 0.587 \\
Jaccard & 0.923 & 0.532 & \\
ISSR & 0.475 & 0.362 & 0.727 \\
Nei and Li & 0.922 & 0.443 & \\
Dice & & & 0.42 \\
Jaccard & & & \\
RAPD+ISSR & 0.922 & 0.632 & 0.727 \\
Nei and Li & 0.472 & 0.374 & 0.423 \\
Dice & 0.832 & 0.232 & 0.532 \\
Jaccard & & & \\
\hline
\end{tabular}

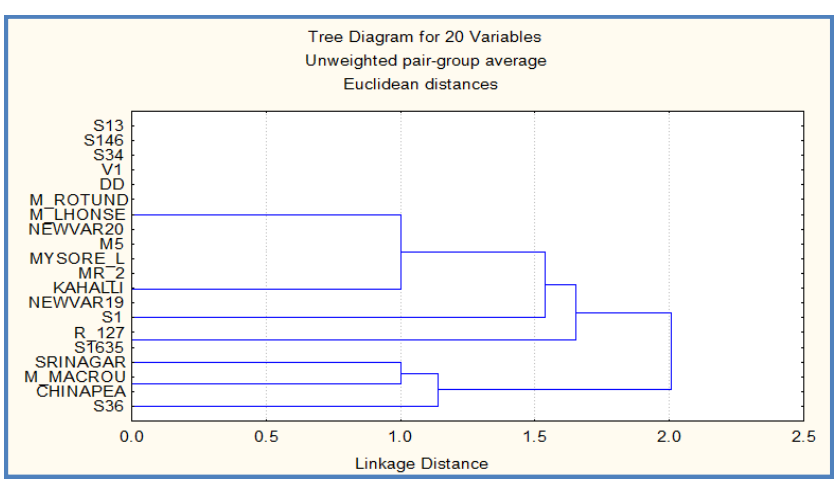

Fig. 3- Cluster analysis of 20 mulberry varieties generated by UPGMA method for cumulative band data obtained by RAPD data

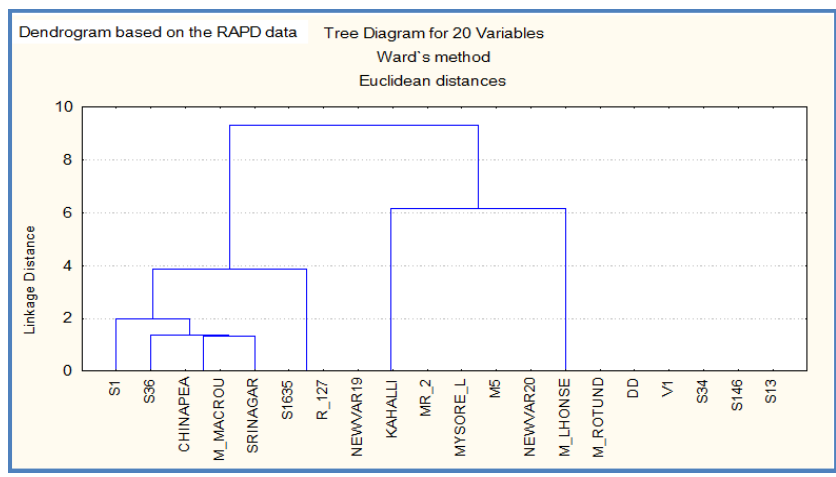

Fig. 4- Dendrogram based on based on RAPD data of 20 mulberry varieties generated by Wards method

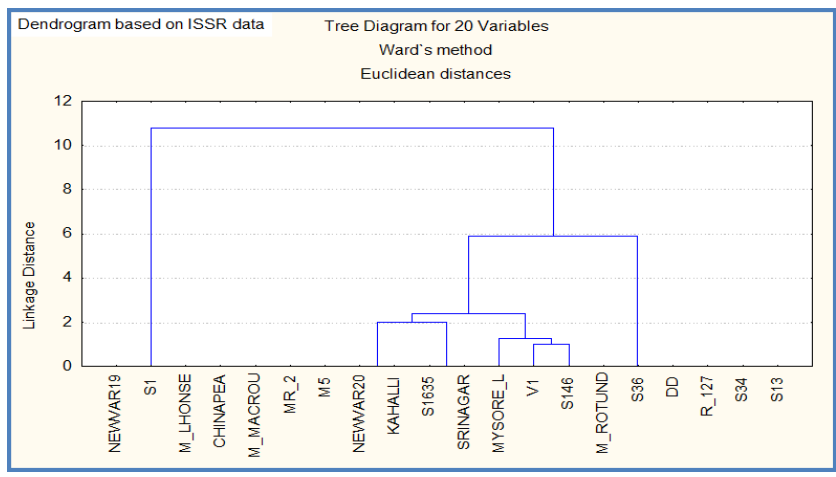

Fig. 5- Dendrogram based on based on ISSR data of 20 mulberry varieties generated by Wards method

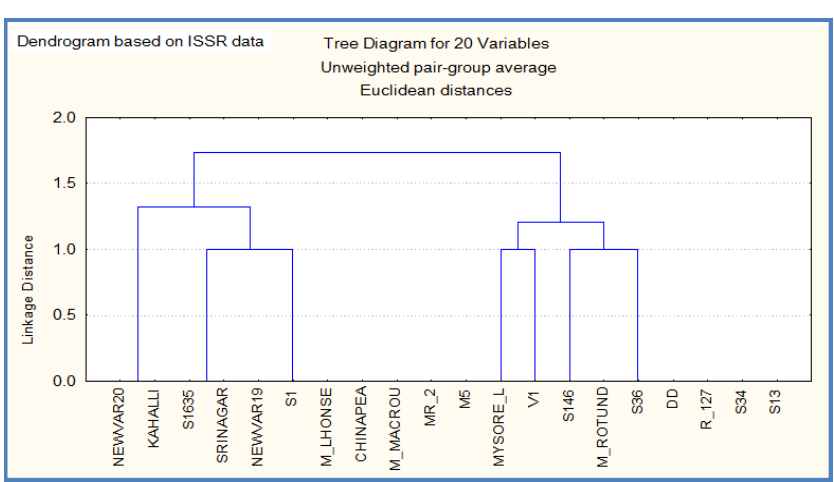

Fig. 6- Dendrogram based on based on ISSR data of 20 mulberry varieties generated by UPGMA method 


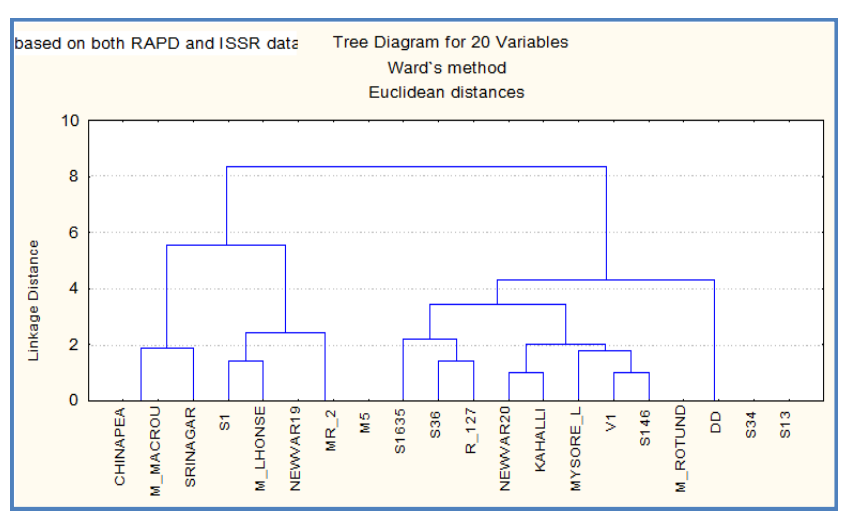

Fig. 7- Dendrogram based on based on RAPD and ISSR data of 20 mulberry varieties generated by Wards method

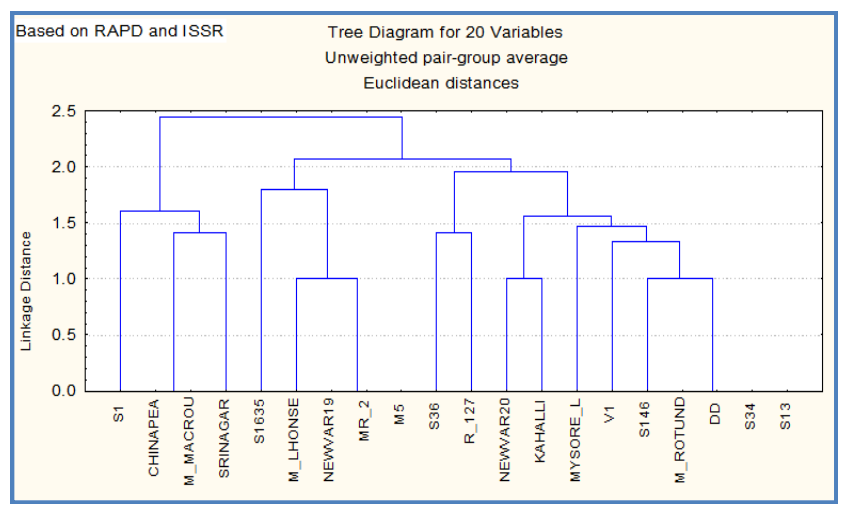

Fig. 8- Dendrogram based on based on RAPD and ISSR data of 20 mulberry varieties generated by UPGMA method

\section{DNA Polymorphism Within the Genotypes}

Analysis of the DNA extracted from twenty mulberry genotypes, from each variety with 8 selected ISSR primers (UBC- 807, 809, $810,811,812,820,825,828)$ and Sixteen primers RAPD such.OPA- 1, OPA-3, OPA-13, OPA-18, OPB-17, OPC-01, OPC02, OPC-08, OPC-10, OPC-12, OPD-11, OPD-13, OPE-07, OPE19, OPF-07 and OPF-17 showed DNA polymorphism among the varieties of the genotypes. Further studies were also conducted with DNA from a single plant for each genotype.

\section{DNA Polymorphism Among the Genotypes}

On the basis of the DNA markers generated, considerable genetic diversity was observed among the varieties. The bands profiles generated by the 16 RAPD primers out which OPD-11 had 75 RAPD bands, out which 61 bands were polymorphic and 14 bands were monomorphic showing clear variability [Fig-1]. These bands were laid in between 300-5000bp with an average of 2 bands per primer with the primer sequence AGCGCCATTG. The number and size of the amplification products varied depending on the sequence of random primers and mulberry accessions. The primers resulted in distinct- both monomorphic and polymorphic banding pattern. Further, the isolation and gel profiling system shows variation in amplification because of the primer sequence. The average number of bands per primers was 4.6 and percentage of polymorphic was $81.3 \%$.

Genetic similarity among the 20 mulberry varieties were estimated on the basis of the ISSR banding profiles generated by each primer with the genomic DNA of the mulberry varieties. The genomic DNA of these mulberry varieties amplified with oligonucleotide primer UBC - 809 generated a total number of 108 ISSR bands. The number of ISSR was specific to each mulberry variety showing a differential distribution on gel profile. The size of the amplified product ranged from $0.5-1.0 \mathrm{~kb}$. Out of these 43 bands, four bands each were recorded in varieties such as 10,16, 17 and 19 respectively. However, varieties such as 5, 4, 9, 11, 14 and 18, recorded three bands each respectively, even though the genomic DNA of mulberry varieties such as 2, 12 and 20 amplified with primer UBC-809 revealed two bands only. It was also noted that only one band was recorded in variety 6 . The data showed a very high ISSR banding pattern to distinguish in mulberry varieties as a diverse character the identification of ISSR banding pattern is important because it follows Mendelian inheritance character, despite, some the varieties were shown thin ISSR banding patterns on gel profile. Despite some of the genomic DNA of mulberry varieties revealed no ISSR banding pattern in varieties such as $2,6,7,12,14$, the data clearly indicates diverse distribution of ISSR banding pattern on gel profile. Therefore it is useful to correct mulberry identity to one another as an additional tool to support RAPD molecular system as shown in [Fig-2]. Out of 8 ISSR primers UBC-809 clearly revealed such variability among the geno-types [Fig-2]. The 8 ISSR primers generated a total of 43 bands, of which 42 were polymorphic, generating $97.6 \%$ polymorphism among the 20 mulberry genotypes.

\section{Genetic Similarity Among Genotypes}

The genetic similarity coefficients among genotypes estimated on the basis of Nei and Li [17] varied from 0.987 to 0.533 with an average genetic similarity of 0.760 in RAPD markers. The same was in the range of 0.923 and 0.532 with an average of 0.727 in ISSR. The Dice coefficients [18] among the genotypes also showed considerable variation. In RAPD, it varied from 0.460 to 0.373 and in ISSR it was between 0.475 and 0.362 . The similarity coefficient among the genotypes estimated on the basis of Jac [19] was between 0.842 and 0.333 , with an average Of 0.587 in RAPD and $0.922,0.443$ and 0.682 in, ISSR and in the pooled data RAPD + ISSR markers, revealed $0.923,0.632$ with an average of 0.727 and $0.472,0.374$ with an average of 0.423 and $0.832,0.232$ with an average of 0.532 respectively. The Pearson's cortion coefficients between different matrices subjected to Mantel test [21] were found to be highly significant $(r=0.435-0.998, p=0.000)$ [Table-5].

The dendrogram realized from the above matrices, RAPD ISSR and the pooled data from both markers using Wards methods of Euclidean distance and UPGMA method grouped the 20 mulberry genotypes into three, four and five clusters [Fig-3], [Fig-4], [Fig-5], [Fig-6], [Fig-7], [Fig-8]. The dendrogram of the both RAPD and ISSR data revealed genetic diversity and relationships of twenty mulberry varieties using UPGMA method. The dendrogram of RAPD of twenty mulberry showed three clusters. The cluster one included varieties such as S13, S146, S34, V1, DD and $M$. rotund which are not related with each other, where as varieties $M$. Ihonse showed relationship with Karanahalli local. The variety Srinagar showed relationship with S36, where as other varieties are diversified with one another [Fig-3]. The varieties Karanahalli local showed relationship with $M$. Ihonse, where as other varieties revealed diversity between each other [Fig-4]. 
Table 5- The Nei's genetic heterozygosity estimated among 20 mulberry varieties

\begin{tabular}{lcccc|}
$\begin{array}{l}\text { Mulberry } \\
\text { varieties }\end{array}$ & $\begin{array}{c}\text { No. of } \\
\text { observed } \\
\text { alleles }\end{array}$ & $\begin{array}{c}\text { No. of } \\
\text { effective } \\
\text { alleles }\end{array}$ & $\begin{array}{c}\text { Genetic } \\
\text { Heterozygosity }\end{array}$ & $\begin{array}{c}\text { Shannon's } \\
\text { Information } \\
\text { Index }\end{array}$ \\
RAPD & & & & \\
S-13 & $1.38+0.48$ & $1.26+0.38$ & $0.14+0.19$ & $0.23+0.28$ \\
S-146 & $1.42+0.50$ & $1.27+0.37$ & $0.15+0.20$ & $0.23+0.88$ \\
S-34 & $1.42+0.50$ & $1.23+0.34$ & $0.13+0.18$ & $0.21+0.27$ \\
V-1 & $1.42+0.50$ & $1.30+0.38$ & $0.16+0.20$ & $0.24+0.29$ \\
M-5 & $1.45+0.50$ & $1.28+0.38$ & $0.14+0.20$ & $0.28+0.29$ \\
Mysore local & $1.36+0.42$ & $1.19+0.34$ & $0.12+0.18$ & $0.17+0.26$ \\
R-175 & $1.25+0.42$ & $1.14+0.30$ & $0.08+0.17$ & $0.14+0.25$ \\
DD & $1.34+0.43$ & $1.22+0.35$ & $0.14+0.18$ & $0.18+0.27$ \\
Srinagar & $1.30+0.46$ & $1.18+0.32$ & $0.12+0.18$ & $0.16+0.26$ \\
MR-2 & $1.45+0.54$ & $1.27+0.36$ & $0.15+0.19$ & $0.266+0.28$ \\
S-1635 & $1.45+0.47$ & $1.27+0.36$ & $0.16+0.19$ & $0.23+0.28$ \\
Karanahallilocal & $1.38+0.47$ & $1.24+0.34$ & $0.14+0.19$ & $0.23+0.27$ \\
S-36 & $1.44+0.49$ & $1.28+0.36$ & $0.18+0.20$ & $0.24+0.27$ \\
M. macroura & $1.46+0.49$ & $1.26+0.33$ & $0.15+0.19$ & $0.23+0.28$ \\
M. rotundiloba & $1.67+0.46$ & $1.45+0.36$ & $0.25+0.19$ & $0.35+0.27$ \\
Chinapeaking & $1.48+0.49$ & $1.26+0.36$ & $0.15+0.18$ & $0.24+0.24$ \\
M. Ihou-seringe & $1.36+0.48$ & $1.23+0.33$ & $0.13+0.19$ & $0.22+0.25$ \\
S-1 & $1.48+0.49$ & $1.28+0.36$ & $0.176+0.20$ & $0.25+0.26$ \\
Assambola & $1.46+0.49$ & $1.26+0.34$ & $0.16+0.19$ & $0.24+0.24$ \\
S-41 & $1.67+0.46$ & $1.40+0.36$ & $0.24+0.19$ & $0.35+0.25$ \\
\hline
\end{tabular}

The dendrogram of ISSR data 20 mulberry varieties revealed that Karanahalli local, S1635, Mysore local, V1 and S146 are related with each other [Fig-5]. In dendrogram Karanahalli local, Srinagar, S1, Mysore local, V1, S145 and S36 [Fig-6]. The RAPD and ISSR data revealed that. M. macrou, Srinagar, S1, M. Ihonse, MR2, s1635, S36, R127, Newvar20, Karanahall Mysore local, V1 and S146 are inter related with other [Fig-7]. Further, [Fig-8] revealed that all the varieties interrelated with other except a few varieties.

Table 6- The Nei's genetic heterozygosity estimated among 20 mulberry varieties

\begin{tabular}{lcccc|} 
Mulberry varieties & $\begin{array}{c}\text { No. of } \\
\text { Observed } \\
\text { alleles }\end{array}$ & $\begin{array}{c}\text { No. of } \\
\text { Effective } \\
\text { alleles }\end{array}$ & $\begin{array}{c}\text { Genetic } \\
\text { Heterozygosity }\end{array}$ & $\begin{array}{c}\text { Shannon's } \\
\text { Information } \\
\text { Index }\end{array}$ \\
\hline ISSR & $1.49+0.49$ & $1.24+0.35$ & $0.15+0.19$ & $0.22+0.28$ \\
S-13 & $1.42+0.50$ & $1.24+0.37$ & $0.16+0.20$ & $0.23+0.88$ \\
S-146 & $1.40+0.50$ & $1.24+0.34$ & $0.14+0.18$ & $0.21+0.27$ \\
S-34 & $1.44+0.50$ & $1.34+0.38$ & $0.17+0.20$ & $0.25+0.29$ \\
V-1 & $1.41+0.50$ & $1.24+0.37$ & $0.15+0.20$ & $0.23+0.29$ \\
M-5 & $1.43+0.42$ & $1.14+0.33$ & $0.11+0.18$ & $0.16+0.26$ \\
Mysore local & $1.24+0.42$ & $1.14+0.31$ & $0.09+0.17$ & $0.13+0.25$ \\
R-175 & $1.44+0.47$ & $1.24+0.35$ & $0.13+0.18$ & $0.19+0.27$ \\
DD & $1.40+0.46$ & $1.14+0.33$ & $0.11+0.18$ & $0.17+0.26$ \\
Srinagar & $1.46+0.50$ & $1.24+0.37$ & $0.16+0.19$ & $0.24+0.28$ \\
MR-2 & $1.45+0.49$ & $1.24+0.36$ & $0.16+0.19$ & $0.24+0.28$ \\
S-1635 & $1.48+0.48$ & $1.26+0.34$ & $0.14+0.19$ & $0.22+0.27$ \\
Karanahalli local & $1.45+0.49$ & $1.28+0.37$ & $0.17+0.20$ & $0.25+0.27$ \\
S-36 & $1.44+0.49$ & $1.27+0.35$ & $0.16+0.19$ & $0.24+0.28$ \\
M. macroura & $1.67+0.46$ & $1.43+0.37$ & $0.24+0.19$ & $0.36+0.27$ \\
M. rotundiloba & $1.45+0.49$ & $1.26+0.36$ & $0.16+0.19$ & $0.24+0.28$ \\
Chinapeaking & $1.48+0.48$ & $1.26+0.34$ & $0.14+0.19$ & $0.22+0.27$ \\
M. Ihou-seringe & $1.46+0.49$ & $1.26+0.37$ & $0.17+0.20$ & $0.25+0.27$ \\
S-1 & $1.45+0.49$ & $1.26+0.35$ & $0.16+0.19$ & $0.24+0.28$ \\
Assambola & $1.48+0.46$ & $1.26+0.37$ & $0.24+0.19$ & $0.36+0.27$ \\
S-41 & & & & \\
\hline
\end{tabular}

Another important point noticed from the dendrogram is the high genetic distance enjoyed in some mulberry varieties from the others while the genotypes of other varieties showed closer relation- ships. The Mai tests [21] between cophenetic correlation mal and its corresponding similarity matrix were found very significant $(r=$ $0.535-0.842, p=0.000$ ) for all dendrogram [Table-6].

The dendrogram of the both RAPD and ISSR data revealed genetic diversity and relationships of twenty mulberry varieties using UPGMA method. The dendrogram of RAPD of twenty mulberry were showed three clusters. Cluster one included varieties such as S13, S146, S34, V1, DD and $M$. rotund which are not related with each other, where as varieties $M$. Ihonse showed relationship with Karanahalli. The variety Srinagar showed relationship with S36, where as other varieties are diversified with one another [Fig-3]. The dendrogram based on RAPD data revealed that S1, S36, Chinapeaking, M. macrou, Srinagar, Karanahalli and M. Ihonse are related with each other [Fig-4]. Similar Observation was made on ISSR data [Fig-5], [Fig-6], [Fig-7], [Fig-8].

\section{Discussion}

The results of the present investigation clearly demon-strate the usefulness of RAPD and ISSR to delineate the in-terrelationships among varieties/ genotypes of 20 mulberry varieties present in Karnataka, India. Although ISSR primers unraveled more polymorphism than RAPD primers, both RAPD and ISSR primers generated almost similar types of genetic rela-tionships among the genotypes and their respective varieties. Using ISSR primers, high genetic variability has been de-tected among closely related cultivars and (or) varieties in many other crop plants [27,28]. Similarly, [29] also obtained high genetic divergence among 11 closely related local cultivars of mulberry with ISSR primers. Likewise, [30] and [16] demonstrated the suitability of RAPD primers in unraveling the genetic relationships among a few genotypes of mulberry indigenous to India. However, there was no report where molecular markers were used to address the problems per-taining to taxonomic identifications in mulberry. Therefore, the data pre-sented in this study suggest the possibility of using DNA markers to decipher the information related to mulberry systematic. Three different algorithms were used to esti-mate the genetic differences among the genotypes and their sub varieties. All the three types of matrix and their corresponding dendrograms showed more or less similar results. However, from the dendrogram it is clear that coeffi-cients of [17] generated trees with deep and distinct nodes. Hence, coefficients of [17] could be of much use in mulberry for phylogenetic studies.

Regarding the genetic relationships of varieties / genotypes, the pair-wise estimation of genetic similarity coefficients and subsequent clustering of the genotypes revealed close genetic similarity among the varieties / genotypes of Morus. The grouping of genotypes of $M$. laevigata as a separate cluster indicated its greater genetic divergence from other species. Further analyses with average genetic dis-tances among the genotypes under each species also re-vealed considerable genetic similarity among varieties. These varieties /genotypes together made an internal group in all the dendrogram obtained in this study. This close similarity among these varieties /genotypes strongly supports the findings of [31,32] that the protein and isozyme profiles of $M$. alba, M. latifolia and $M$. bombycis are so close that these species should be joined together under one species. Furthermore, it is to be noted that the genetic variation at the DNA level is much more prominent than that at the 
protein level, because of the codon degeneracy. Approximately $29 \%$ of mutations occur-ring at the nucleotide level cannot be detected by amino acid changes [26]. An additional $70-75 \%$ of amino acid substitutions cannot be detected by protein electrophoresis because of the maintenance of net protein charge. In total, the detected genetic variation via allozyme is expected to be at least five to six fold less than at the DNA level [26]. Thus, the close relationships observed among these mulberry varieties is the true reflection of the genetic similarity present even at the DNA level. Thus, the taxonomists working on this aspect of mulberry should give serious thought in this direction by undertaking a more detailed work to resolve the ambiguity over the separate species status of these genotypes. Similarly, the high fertility (>90\%) obtained in controlled hybridization among them.

Similar findings of [33] on M. Indica, M. alba, M. latifolia and $M$. bombycis supports the fact that these species should not be treated as separate species, as the very definition of species defined by [34] emphasizes reproductive isolation of species. Further, in most of the conventional methods of systematic, floral features play a crucial role in judging the varieties. However, in mulberry, [35] found a gradual reduction in one of the sexes on bisexual flowers leading to unisexuality. Likewise, [36] and [37] observed sex reversal upon hormonal application or pruning of branches of the plant. [38] reported that high temperature, long day and full daylight favored femaleness in mulberry. These reports thus clearly suggest that floral characteristics cannot be taken as the sole diagnostic character for identification of species in mulberry. Therefore, it is clear that the classifications based on morphological, anatomical, or even biochemical charac-ters alone do not identify the varieties accurately in a highly heterozygous plant like mulberry. Hence, it is essential to undertake detailed studies of this genus, using biochemical, genetic and morphofloral characteristics to get over the confusion associated with species identity in mulberry.

The position of mulberry varieties in relation to other varieties needs special mention, as this method $M$. Ihonse and Karanahalli comprising was found to have an intermediate genetic relationship between the other group comprising S1, R-127, S1635 and Srinagar, M. macru and S36 When the total genotypes were analyzed indi-vidually, all varieties together into a separate cluster. However, when the varietal variability was analyzed showed more closeness to the other group. Cross hybridization of different varieties of Morus showed produced a high per-centage $(>80 \%)$ of fertile seeds, whereas a cross between some of mulberry varieties failed to develop any fertile seeds [33]. These findings, along with the result of the present investi-gation, suggest that as indicated in dendrogram $3,4,5,6,7$ and 8. Similar observations were also made by [39] based on the morphological features of $M$. indica, $M$. alba and $M$. laevigata, suggesting $M$. indica and $M$. alba as similar species. Our findings on twenty mulberry varieties with the molecular markers en -dorse this view to a certain extent, but considering the small number of varieties/ genotypes used for this analysis, it is desirable to undertake a detailed study with a greater number of genotypes to identify the taxonomic position of this very important mulberry species.

The separate identity of mulberry varieties under different clusters as indicated in [Fig-4]. and S1 and S36 varieties were quite obvious from this study, as in all analyses, exhibited higher genetic distance from the other varieties. This is not surprising, since most of the genotypes reported that under different ploidy [40]. However, in the present study, we used diploid genotypes to avoid the differences at ploidy level. The floral phenology of different mulberry varieties are also found to be different each other, as the length of the catkins in these varieties varied $[37,41]$. Simi-larly, controlled hybridizations between mulberry varieties failed to develop any fertile seeds. These findings together with the results of our study clearly show that $S$ and $V 1$ varieties are genetically different from other mulberry varieties and could be considered as separate clusters.

The population structure analyses further demonstrated the genetic difference of twenty mulberry varieties and the closer relationships the total heterozygosity within the population $(\mathrm{Ht})$ and be-tween populations (Dst) and the genetic differentiation coefficients (Gst) were much higher than the same between other varieties. These values clearly suggest higher genetic divergence of $S$ varieties from the other varieties. This is further evidenced from the low gene flow $(\mathrm{Nm})$ from some of the mulberry varieties to the other. The exchange of genes between populations of homogenizes allele and frequencies be-tween populations determine the relative effect of se-lection and genetic drift. High gene flow between populations precludes local adaptation and also impedes the process of speciation. In popu-lation genetics, a value of gene flow $(\mathrm{Nm})<1.0$ (fewer than one migrant per generation into a population) or equivalently, a value of gene differentiation (GST) $>0.25$ is gener-ally regarded as the threshold quantities beyond which significant population differentiation occurs [42] [Table-5], [Table-6], [Table-7], [Table-8], [Table-9].

Table 7- Gene differentiation coefficients and genetic diversity in the populations of 20 mulberry varieties (Data continues in table 8

\begin{tabular}{|c|c|c|c|c|c|}
\hline \multicolumn{2}{|c|}{ Mulberry varieties } & M-5 & Mysore local & R-175 & DD \\
\hline \multirow[t]{5}{*}{$S-13$} & $\mathrm{Ht}$ & 0.171 & & & \\
\hline & $\mathrm{Hs}$ & 0.162 & & & \\
\hline & DST & 0.049 & & & \\
\hline & GST & 0.104 & & & \\
\hline & $\mathrm{Nm}$ & 1.747 & & & \\
\hline \multirow[t]{5}{*}{ S146 } & $\mathrm{Ht}$ & 0.203 & 0.101 & & \\
\hline & $\mathrm{Hs}$ & 0.264 & 0.257 & & \\
\hline & DST & 0.049 & 0.043 & & \\
\hline & GST & 0.177 & 0.117 & & \\
\hline & $\mathrm{Nm}$ & 2.274 & 1.705 & & \\
\hline \multirow[t]{5}{*}{ S 34} & $\mathrm{Ht}$ & 0.221 & 0.228 & 0.139 & \\
\hline & $\mathrm{Hs}$ & 0.162 & 0.152 & 0.155 & \\
\hline & DST & 0.063 & 0.075 & 0.045 & \\
\hline & GST & 0.273 & 0.331 & 0.268 & \\
\hline & $\mathrm{Nm}$ & 1.569 & 1.605 & 1.278 & \\
\hline \multirow[t]{5}{*}{ V1 } & $\mathrm{Ht}$ & 0.224 & 0.227 & 0.323 & 0.231 \\
\hline & $\mathrm{Hs}$ & 0.201 & 0.184 & 0.306 & 0.201 \\
\hline & DST & 0.023 & 0.143 & 0.223 & 0.318 \\
\hline & GST & 0.079 & 0.439 & 0.456 & 0.272 \\
\hline & $\mathrm{Nm}$ & 0.717 & 0.736 & 0.718 & 0.745 \\
\hline
\end{tabular}

The very low $\mathrm{Nm}$ present in $\mathrm{S}$ varieties further reflects the reproductive isolation it holds from other varieties/genotypes of mulberry. Similar observation was made by [34] since reproductive isolation is one of the important criteria considered for species recognition (Darwin this can be treated as a separate species under the genus Morus. Thus, from the overall studies, it can be con- 
cluded that the mulberry varieties / genotypes boundary is not very rigid in mulberry; identifi-cation of taxa based on morphofloral characters alone often generates misleading results. Thus, an approach integrating morphological, biochemical and genetic and (or) molecular parameters is required to resolve the problems pertaining to the taxonomic positions of most of the presently designated varieties / genotypes in mulberry. Furthermore, S and other mulberry varieties can be con-sidered to be a separate group of mulberry, while the other varieties may be joined together and treated as separate group etc.

Table 8- Gene differentiation coefficients and genetic diversity in the populations of 20 mulberry

\begin{tabular}{|lccccc} 
Varieties & & Karanahalli local & S-36 & M. macroura & M. rotundiloba \\
Srinagar & Ht & 0.223 & & & \\
& Hs & 0.202 & & & \\
& DST & 0.039 & & & \\
& GST & 0.204 & & & \\
MR-2 & Nm & 1.847 & & & \\
& Ht & 0.203 & 0.202 & & \\
& Hs & 0.154 & 0.147 & & \\
& DST & 0.039 & 0.044 & & \\
& GST & 0.177 & 0.227 & & \\
Karanahalli & Nm & 2.164 & 1.805 & & \\
local & Ht & 0.232 & 0.218 & 0.209 & \\
& Hs & 0.161 & 0.142 & 0.155 & \\
& DST & 0.062 & 0.066 & 0.064 & \\
& GST & 0.253 & 0.322 & 0.249 & \\
S-165 & Nm & 1.249 & 1.046 & 1.279 & \\
& Ht & 0.314 & 0.317 & 0.321 & 0.221 \\
& Hs & 0.211 & 0.184 & 0.207 & 0.202 \\
& DST & 0.133 & 0.143 & 0.134 & 0.119 \\
& GST & 0.369 & 0.309 & 0.366 & 0.371 \\
& Nm & 0.827 & 0.624 & 0.818 & 0.848 \\
\hline
\end{tabular}

Table 9- Gene differentiation coefficients and genetic diversity in the populations of 20 mulberry varieties

\begin{tabular}{|lccc|}
\hline Mulberry varieties & & & S 41 \\
\hline M. Ihou-seringe & $\mathrm{Ht}$ & 0.191 & \\
& $\mathrm{Hs}$ & 0.152 & \\
& $\mathrm{DST}$ & 0.039 & \\
$\mathrm{~S}-1$ & $\mathrm{GST}$ & 0.204 & \\
& $\mathrm{Nm}$ & 1.947 & \\
& $\mathrm{Ht}$ & 0.203 & \\
& $\mathrm{Hs}$ & 0.164 & \\
& $\mathrm{DST}$ & 0.039 & \\
& $\mathrm{GST}$ & 0.187 & \\
Assambola & $\mathrm{Nm}$ & 2.174 & \\
& $\mathrm{Ht}$ & 0.222 & 0.204 \\
& $\mathrm{Hs}$ & 0.16 & 0.152 \\
& $\mathrm{DST}$ & 0.062 & 0.076 \\
& $\mathrm{GST}$ & 0.283 & 0.332 \\
& $\mathrm{Nm}$ & 1.269 & 1.006 \\
\hline
\end{tabular}

The result presented in the present study demonstrated the appropriacy of using RAPD and ISSR markers to characterize genetic diversity among 20 promising varieties/cultivars /genotypes of mulberry. Differential polymorphism was noted in 20 cultivars of mulberry showing variation in percentage of polymorphic bands from $81.3 \%$ to $97.6 \%$ in using 16 primers RAPD and 8 ISSR primers. The observed high proportion of polymor-phic loci reveals profound intraspecific variation among the mulberry cultivars. Significant genetic variations by RAPD and ISSR markers have also been reported in other species at cultivar level [43]. Wide genetic distances determined $[19,22,24]$ genetic distance reveals relatively high genetic variation among 20 mulberry cultivars. The observed intra-specific differ-ences among 20 mulberry cultivars could be ascribed to the fluctuating micro and macro climatic conditions of habitat. $[19,22,24]$ analysis of RAPD and ISSR data also reveals that all mulberry cultivars belonging to the state of Karnataka are genetically closer and diversified other than the cultivars originally belonging to the distant habitat in the state of Karnataka. The greater sensitivity of RAPDs and ISSR obtained in the results of mulberry cultivars, diversity may be derived from rapid evolution of non-coding, repetitive DNA sequences detected by RAPD and ISSR. This hypothesis has been corroborated by Plomion, et al. [44].

\section{Reference}

[1] Yokoyama T. (1962) Synthesized Science of Sericulture, Japan, 39-46.

[2] Vavilov N.I. (1926) Bulletin of Applied Botany, 16(2).

[3] Das B.K., Das C. and Mukherjee K. (1994) Indian J. Seric., 33, 188-190.

[4] Dongre A.B., Bhandarkar M.R. and Parkhi V.T. (2006) Indian J. Gent., 66(4), 279-282.

[5] Welsh J. and McClelland M. (1990) Nucl. Acids Res., 18, 72137218.

[6] Hu J. and Quirose C.F. (1991) Plant Cell Rep., 10, 505-511.

[7] Wilde J.C., Waugh R. and Powell W. (1992) Theor. Appl. Genet., 83, 871-877.

[8] Demeke T., Adams R.P. and Chibbar R. (1992) Theor. Appl. Genet., 84, 990-994.

[9] Halward T.M., Stalker H.T., La Rue E.A. and Kochert G. (1992) Plant Mol. Biol., 18, 315-325.

[10]Yu K. and Pauls K.P. (1993) Plan. Mol. Biol., 22, 269-277.

[11]Zietkiewicz E., Rafalski A. and Labuda D. (1994) Genomics, 20, 176-183.

[12]Souframanien J. and Gopalakrishna T. (2004) Theor. Appl. Genet., 109, 1687-1693.

[13]Basha S.D. and Sujatha M. (2007) Euphytica., 156, 375-386.

[14]Porebski S., Bailey L.G. and Baum B.R. (1997) Plant Mol. Bio Rep., 15(1), 8-15.

[15]Williams J.G.K., Kubelik A.R., Livak K.J., Rafalski J.A. and Tingey S.V. (1990) Nucleic Acids Res., 6531-6535.

[16]Chatterjee S.N., Nagaraja G.M., Srivastava P.P. and Naik G.Y. (2004) Genetica., 4, 1-11.

[17]Nei M. and Li W. (1979) Proc. Natl. Acad. Sci. USA, 74, 52675273.

[18]Sneath P.H.A. and Sokal R.R. (1973) Numerical taxonomy, WH Freeman, San Francisco, Calif.

[19]Jaccard P. (1901) Bull Soc. Vandoise Sci. Nat., 37, 547-579.

[20]Felsenstein J. (1993) Phylip Version 3.5c., Department of Genetics, University of Washington, Seattle, Washington. 
[21]Mantel N. (1967) Cancer Res., 27, 175-178.

[22]Nei M. (1973) Proc. Natl. Acad. Sci. USA, 70, 3321-3323.

[23]Yeh F.C. (1998) Popgene 16. Version 1.31. Agriculture an estry Molecular Biology and Biotechnology Center, Uni' of Alberta and Center for International Forestry Research ada.

[24]Nei M. (1972) Am. Nat., 106, 283-292.

[25]Wright S. (1943) Genetics, 28, 114-138.

[26]Nei M. (1987) Molecular Evolutionary Genetics, Columbia Univer-sity Press, New York.

[27]Tsumura Y., Ohba K. and Strauss S.H. (1996) Theor. Appl. Genet., 92, 40-45.

[28]Bomet B., Goraguer R., Joly G. and Branchard M. (2002) Genome, 45, 481-484.

[29]Vijayan K. and Chatterjee S.N. (2003) Euphytica., 131, 53-63.

[30]Bhattacharya E. and Ranade S.A. (2001) BMC Plant Biol., 3.

[31]Hirano H. (1977) Jpn. Agric. Res., Q(11), 228-233.

[32]Hirano H. (1982) Photochemistry, 21, 1513-1518.

[33]Das B.C. and Krishnaswami S. (1965) Indian J. Seric., 4, 1-8.

[34]Darwin C. (1859) On the origin of species, Murray, London.

[35]Mukherjee S.K. (1965) Indian J. Seric., 4, 1-7.

[36]Das B.K. and Mukherjee S.K. (1992) Indian J. Seric., 3, 173175.

[37]Tikader A., Vijayan K., Raghunath M.K., Chakraborti S.R., Roy B.N. and Pavankumar T. (1995) Euphytica, 84, 115-120.

[38]Minamizawa K. (1963) Bull Fac. Tokyo Noko Digaku., 7, 4-47.

[39]Gururajan M.K. (1960) Indian Silk J., 1, 12-15.

[40]Das B.C. (1961) Caryologia., 14, 159-162.

[41]Das B.C., Prasad D.N. and Krishnaswami S. (1970) Indian J. Seric., 9, 59-63.

[42]Slatkin M. (1987) Science, 236, 787-792.

[43]Colombo C.G., Second T.L. and Charier A. (1998) Genet. Mol. Biol., 21, 69-84.

[44]Plomion C., O'Malley D.M. and Durel C.E. (1995) Theor. Appl. Genet., 90, 1028-1034. 